\title{
What Are The Factors That Affect Post COVID 1st Month's Continuing Symptoms?
}

\author{
Berna Akinci Ozyurek ${ }^{1}$, Tugce Sahin Ozdemirel ${ }^{2}$, Esma Sevil Akkurt ${ }^{3}$, Derya Yenibertiz ${ }^{4}$, \\ Tilbe Saymaz ${ }^{2}$, Sertac Buyukyaylaci Ozden², and Zehra Eroglu² \\ ${ }^{1}$ Affiliation not available \\ ${ }^{2}$ Department of Chest Disease, University of Health Sciences Ankara Atatürk Chest \\ Diseases and Chest Surgery Training and Research Hospital, Ankara-Turkey. \\ ${ }^{3}$ Department of Chest Disease, University of Health Sciences Ankara Atatürk Chest \\ Diseases and Chest Surgery Training and Research Hospital, Ankara-Turkey \\ ${ }^{4}$ University of Health Sciences Keçiören Training and Research Hospital, Ankara-Turkey.
}

February 16, 2021

\begin{abstract}
ABSTRACT Aim: The aim of our research was to investigate retrospectively the relationship between the symptoms and general characteristics, initial laboratory values and treatments in patients who had COVID- 19 and who applied to the chest diseases outpatient clinic for control after 1 month. Methods: Three hundred fifteen patients who were diagnosed with COVID- 19 and applied to the chest diseases outpatient clinic between May 2020 and August 2020 for control in the 1st month were included in the study. Patient information was collected from the hospital information system and the e-pulse system. Results: Females accounted for $50.2 \%$ of the our patients and their mean age was $47.98 \pm 14.81$ (19-88) years. $14.3 \%$ (n: 45) of the individuals were 65 years of age and older. $20.6 \%$ (n: 65 ) of our patients were smoking. $70.2 \%$ (n: 221 ) of our patients were treated at home. 133 patients had at least one comorbid disease. The patients most frequently reported cough, dyspnea, weakness, myalgia and diarrhea. The most common symptoms were cough, dyspnea, weakness and myalgia in the first month. It was determined that the symptoms had persisted in patients who had been hospitalized, had dual therapy, had comorbid diseases and had more common pathologies in their pulmonary imagings. Conclusion: Symptoms may persist for a long time in hospitalized patients, in patients with COVID-19-related pneumonia and concomitant chronic diseases and in patients with high d-dimer and high CRP at the time of admission. Patients are informed that their symptoms may last for a long time, unnecessary hospital admissons can be avoided.
\end{abstract}

\section{What Are The Factors That Affect Post COVID 1st Month's Continuing Symptoms?}

Berna Akinci Ozyurek ${ }^{1}$, Tugce Sahin Ozdemirel ${ }^{1}$, Esma Sevil Akkurt ${ }^{1}$, Derya Yenibertiz ${ }^{2}$, Tilbe Saymaz ${ }^{1}$, Sertaç Büyükyaylacı Özden ${ }^{1}$, Zehra Eroğlu ${ }^{1}$

1. Department of Chest Disease, University of Health Sciences Ankara Atatürk Chest Diseases and Chest Surgery Training and Research Hospital, Ankara-Turkey.

2. University of Health Sciences Keçiören Training and Research Hospital, Ankara-Turkey.

\section{Correspondence and reprints to:}

Berna Akinci Ozyurek

Department of Chest Disease, University of Health Sciences Ankara Atatürk Chest Diseases and Chest Surgery Training and Research Hospital, Ankara-Turkey. 
Phone: +90 554419103, Fax: +90 3125677700

E-mail: drberna_1982@yahoo.com

This study is not under consideration by any other journal at the same time and that it has not been accepted for publication elsewhere, in any language. I attest that this paper has been read and approved by all co-authors, and there is no conflict of interest to declare.

\section{ABSTRACT}

Aim:

The aim of our research was to investigate retrospectively the relationship between the symptoms and general characteristics, initial laboratory values and treatments in patients who had COVID- 19 and who applied to the chest diseases outpatient clinic for control after 1 month.

\section{Methods:}

Three hundred fifteen patients who were diagnosed with COVID- 19 and applied to the chest diseases outpatient clinic between May 2020 and August 2020 for control in the 1st month were included in the study. Patient information was collected from the hospital information system and the e-pulse system.

\section{Results:}

Females accounted for $50.2 \%$ of the our patients and their mean age was $47.98 \pm 14.81$ (19-88) years. $14.3 \%$ (n: 45 ) of the individuals were 65 years of age and older. $20.6 \%$ (n: 65 ) of our patients were smoking. $70.2 \%$ (n: 221) of our patients were treated at home. 133 patients had at least one comorbid disease. The patients most frequently reported cough, dyspnea, weakness, myalgia and diarrhea. The most common symptoms were cough, dyspnea, weakness and myalgia in the first month. It was determined that the symptoms had persisted in patients who had been hospitalized, had dual therapy, had comorbid diseases and had more common pathologies in their pulmonary imagings.

\section{Conclusion:}

Symptoms may persist for a long time in hospitalized patients, in patients with COVID-19-related pneumonia and concomitant chronic diseases and in patients with high d-dimer and high CRP at the time of admission. Patients are informed that their symptoms may last for a long time, unnecessary hospital admissons can be avoided.

Key Words: Post COVID, symptoms, persistent

WHAT'S KNOWN? Long COVID is the name used by patients to identify symptoms of COVID-19 that persist after acute illness. The working definitions of 'post-acute' (symptoms after 3-4 weeks) and 'chronic' (symptoms after 12 weeks) COVID-19 have not yet been officially confirmed. The cause of persistent symptoms is unknown, but it probably involves several different mechanisms of disease, including an inflammatory reaction with a vasculitic component

WHAT'S NEW? If patients with d-dimer and crp elevation at the time of diagnosis with cocomitant diseases and with widespread pneumonia in thorax ct are informed that their symptoms may last for a long time, unnecessary hospital admissons can be avoided.

\section{INTRODUCTION}

In studies conducted on reports of pneumonia cases with unknown etiology in Wuhan, China's Hubei Province, on 31 December 2019, it was determined that a new coronavirus (2019-nCoV) had not been detected in humans before and that the name of the disease had been accepted as COVID-19. The cases were reported in 113 countries outside of China, where the first epidemic started. It was defined as a global (pandemic) epidemic on 11 March due to the spread and severity of the virus. The first case was detected in our country on 11 March. As in the world, the number of cases in our country has increased day by day (1). 
Although the virus is found in the feces and urine of affected individuals, the disease spreads mainly through respiratory droplets (2).

Patients can present with asymptomatic or flu-like symptoms. It may show a different clinical course from pneumonia to respiratory failure and may have a fatal course $(3,4)$.

Fever, cough, shortness of breath, myalgia and fatigue are most common; sputum, hemoptysis, loss of sense of smell and taste, sore throat, headache, chest pain, diarrhea are also common symptoms of COVID-19 infection $(5,6)$. In mild cases, symptoms continue for 2 weeks. It goes on for up to 3-6 weeks in severe cases. Symptoms can get worse in a week or so. Approximately 2-8 weeks after the onset of symptoms, deaths were also seen.

The follow-up and care of patients has been arranged according to the COVID-19 guide prepared by the Ministry of Health, General Directorate of Public Health, since the onset of the disease in our country and those with moderate illness at the beginning of the outbreak were hospitalized, and those with serious illness continued to be hospitalized in the subsequent periods. There have also been changes in treatment recommendation. It was found that some symptoms also existed in the outpatient clinic controls.

The aim of our research was to investigate retrospectively the relationship between the symptoms and general characteristics, initial laboratory values and treatments in patients who had Covid 19 and who applied to the chest diseases outpatient clinic for control after 1 month.

\section{MATERIALS-METHODS}

Three hundred fifteen patients who were diagnosed with COVID- 19 and applied to the chest diseases outpatient clinic between May 2020 and August 2020 for control in the 1st month were included in the study.

Patient informations were collected from the hospital information system and the e-pulse system. Patients' general characteristics (age, gender, history of smoking, treatment regimen, additional diseases), initial symptoms and ongoing symptoms within the first month, radiological characteristics, laboratory parameters (hemogram values, inflammatory markers, d-dimer) and hospitalization status were reported.

The approval for the study was obtained from the Medical Specialty Education Board of our hospital (689$27 / 8 / 2020)$.

\section{STATISTICAL ANALYSIS}

The data obtained was evaluated in a computer environment using the IBM-SPSS (Version 20.0) statistical package program. For descriptive statistics, mean, standard deviation, minimum-maximum, median and 2575 quartile values were used. The Shapiro-Wilk test was used to compare continuous results, and the Mann Whitney U and Kruskall Wallis tests were used because, as a result of the normality test, they did not comply with the normal distribution. McNemar and Wilcoxon tests were used for dependent group comparisons. For statistical significance, p[?]0.05 has been accepted.

\section{RESULTS}

Females accounted for $50.2 \%$ of the our patients and their mean age was $47.98+-14.81$ (19-88) years. $14.3 \%$ (n: 45) of the individuals were 65 years of age and older, $34.3 \%$ (n: 108) had no findings in their lung computed tomography (CT) and chest X-rays. 20.6\% (n: 65) of our patients were smoking and $70.2 \%$ (n: 221) of our patients were treated at home. 133 patients had at least one comorbid disease. Hypertension (HT) was determined in 43 patients, asthma was determined in 29 patients, diabetes mellitus (DM) was determined in 25 patients, coronary artery disease (CAD) was determined in 15 patients, chronic obstructive pulmonary disease (COPD) was determined in 12 patients, neurological disease was determined in 7 patients, a history of malignancy was determined in 7 patients (2 patients with lung cancer , 3 patients with thyroid cancer, 1 patient with brain cancer, 1 patient with osteosarcoma), hypothyroidism was determined in 5 patients, rheumatological disease was determined in 4 patients, renal failure 3 patients and bronchiectasis 
was determined in 3 patients. In addition to treatment with Favipiravir and/or Hydroxychloroquine, 47 patients received empiric antibiotic therapy, 33 patients received corticosteroid therapy and 23 patients received both antibiotic and corticosteroid therapy. 119 patients received prophylactic enoxaparin and 4 patients received enoxaparin at the therapeutic dose.

General characteristics of the study group are presented in Table 1.

When the symptoms of the study group were evaluated, while $7 \%$ (n: 22 ) of the subjects were asymptomatic in the first part of the study, 27.3\% (n: 86) of the subjects were found to be asymptomatic in the 1-month period ( $\mathrm{p}<0.001)$. It was found that the symptoms of fever, myalgia, diarrhea, dyspnea, cough, loss of taste and smell and sore throat decreased within 1 month of the first period when the contrast of the two periods was examined (Table 2). The symptom distribution of the study group by period is shown in Table 2 .

The median lymphocyte percent was 26.00 (17.75-33.50) in the first part of the analysis, and 27.00 (21.2034.20 ) in the calculation one month later, when certain laboratory values of the study group were analyzed, and there was no difference between the two times. On the other hand, although the values of neutrophils, neutrophils/lymphocytes (NLR) and C-reactive proteins (CRP) decreased over time, the values of platelets and D-dimers increased (Table 3). The distribution of such laboratory values by time is shown in Table 3 .

In our study, no statistically significant difference was found between age, gender and smoking status ( $>0.005$ for each) when the distribution of individuals with persistent symptoms was examined after 1 month. It was determined that the symptoms had persisted in patients who had been hospitalized, had dual therapy, had comorbid diseases and had more common pathologies in their pulmonary imagings (Table 4).

182 patients had no comorbidities, 115 of those without comorbidity continued to have symptoms in the first month. 114 of those with comorbid diseases continued to have symptoms in the first month. Table 4 describes the distribution of general characteristics of the study group according to the occurrence of symptoms after 1 month.

Although there were no symptoms in 7 patients received antibiotic therapy and in 1 patient received antibiotic and corticosteroid therapy in the first month, all patients received corticosteroid therapy had at least one symptom in the first month $(\mathrm{p}<0.001)$.

Initial D-dimer, initial CRP and the values of platelet, D dimer and CRP in the first month were detected to be higher in patients with persistens symptoms when the laboratory values of patients whose symptoms continue after 1 month were examined. No difference was found between the values of initial Neutrophil\%, Lymphocyte\% and NLR and the first month (Table 5).

The distribution of laboratory values for the study group based on the presence of symptoms after 1 month is shown in Table 5.

When the laboratory values of the individuals according to the treatment received in our study were examined; only those receiving hydroxychloroquine had lower initial D-dimer, 1st month lymphocyte and 1st month D-dimer levels, whereas those undergoing dual therapy had higher 1st month CRP levels. (Table 6). In the subgroup analysis, no statistically difference was found in the initial and 1st month NLR values. The distribution of laboratory values by treatment received by the research group is shown in Table 6 .

\section{DISCUSSION}

All people of all age groups may be infected with SARS-CoV-2. Age was one of the risk factors rapidly and lead to death especially in elderly people and in patients with chronic diseases (8). The infection of COVID-19 can affect both men and women. However, its incidence and severity is higher in males than in females.

A study of 138 hospitalized patients with COVID-19 showed that the median age was 56 years and 75 $(54.3 \%)$ were male while $63(45.7 \%)$ were female $(9)$. Almost half $(46.4 \%)$ of patients had an underlying health condition in a retrospective analysis $(\mathrm{n}=138)$ of patients with COVID-19 (9). 
According to the National Health Commission of China (NHC), approximately $80 \%$ of deaths were reported among patients over 60 years of age while $75 \%$ had previous health problems including diabetes and cardiovascular disease (10).

No specific consensus on patient hospitalization or discharge has been reached for infection with COVID-19. Studies show that around $14 \%$ of those infected with COVID-19 have a serious illness and $6 \%$ of those infected are critically ill so $20 \%$ of all cases need to be seriously hospitalized (11).

Hospitalization is recommended for patients over 50 years of age and all age groups with positive CT findings (12).

In our study the female-male ratio and the rate of comorbid diseases were similar to the literature. Cardiovascular diseases, chronic lung diseases and DM were the most common accompanying diseases. Our average age was $47.98+-14.81$ years of age. Mortality has not been observed in our patients due to mild to moderate cases and younger patients. The patients $\% 70$ were given treatment at home. The fact that we have a younger population compared to China and the USA explains this situation.

The most COVID-19 cases (> 70\%) show ground glass opacities with consolidation and interstitial and/or interlobular septal thickening in Thorax CT (13). COVID-19 predominant CT findings are bilateral, peripheral and basal predominant ground-glass opacity, consolidation, or both (14). Air bubble signs and nodules are rare findings $(15,16)$. In 3\%-13\% of COVID-19 pneumonia patients. nodules were identified $(17,18)$, which was lower than that seen in other types of viral pneumonia (19).

All but one of the patients had at least one ground glass or consolidation on their CT scans. Nodular infiltration has been observed in one patient. Ground-glass opacity. with or without consolidation is the main feature of the disease.

The most common symptoms were fever (98\%) followed by cough ( $76 \%)$ with more than half $(55 \%)$ of patients developing dyspnea in a study $(\mathrm{n}=41)$ conducted by Huang et al. in patients with confirmed COVID-19 infection (20).

In a large study $(\mathrm{n}=1.099)$ from China. Guan et al. reported that $67.8 \%$ of COVID-19 patients had cough while $33 \%$ had sputum production and $18.7 \%$ had shortness of breath (21). In a retrospective study $(\mathrm{n}=138)$ of hospitalized COVID-19 patients. $10 \%$ of patients reported nausea and diarrhea (9).

A variety of studies have recorded a wide incidence rate of asymptomatic infections ranging from 1.6 to $56.6 \%$ (22-28). Asymptomatic patients typically experience none of the aforementioned clinical signs and/or symptoms. according to these studies. Furthermore, this subgroup of patients has few to no radiological imaging anomalies. While some with asymptomatic infection may develop into symptomatic cases, most progress is without clinical deterioration. The most common symptoms recorded in our research were cough, shortness of breath, weakness, myalgia and diarrhea. Seven percent of our patients were initially asymptomatic.

It has been accepted that smoking raises the risk of viral infections and influenza. Similar knowledge has been accepted for the COVID-19 pandemic. Smoking has been reported to be correlated with the incidence of the disease and the seriousness of the clinical course (29). Of our patients 20.6 per cent (n: 65 ) have been smoked.

No drugs for effective treatment of COVID-19 have been approved to date $(30,31)$. Treatment is tailored to the severity of the condition and individual heterogeneity.

Updated periodically from the beginning of the pandemic in our country, according to T.C. The Scientific Advisory Board of the Ministry of Health Adult Patient Management Guidelines, if there are no contraindications, hydroxychloroquine and/ or favipravir treatment is recommended for patients with COVID-19. 58.7\% of our patients received favipiravir, $24.8 \%$ received hydroxychloroquine and $16.5 \%$ received favipiravir and hydroxychloroquine. The symptoms of patients who received dual therapy at the beginning of treatment 
were observed to continue in the first month. This situation can be explained by the fact that these patients are heavier than other patients at the time of diagnosis and require more hospitalization.

Long COVID is the name used by patients to identify symptoms of COVID-19 that persist after acute illness (32). The working definitions of 'post-acute' (symptoms after 3-4 weeks) and 'chronic' (symptoms after 12 weeks) COVID-19 have not yet been officially confirmed $(33,34)$.

People with long COVID experience a confounding variety of recurrent and fluctuating symptoms, including cough, dyspnea, fever, sore throat, chest pain, palpitations, cognitive deficiencies, myalgia, neurological symptoms, skin rashes, and diarrhea. [33, 35-39); some of which also have persistent or intermittent low oxygen saturation (40).

In our study, cough, dyspnea, weakness and myalgia were the most common in the first month. It was determined that the symptoms had persisted in patients who had been hospitalized, had dual therapy, had comorbid diseases and had more common pathologies in their pulmonary imagings.

Also, all patients who started corticosteroid therapy at the beginning had at least one symptom in the first month. Corticosteroid therapy was thought to be related to the initiation of patients with severity pneumonia.

The cause of persistent symptoms is unknown, but it probably involves several different mechanisms of disease, including an inflammatory reaction with a vasculitic component (41).

Recent studies estimated that $10-20 \%$ of people are still ill after 3 weeks and $1-3 \%$ are still severely ill after 12 weeks $(34,42)$.

In individuals with conditions such as asthma, diabetes and autoimmune disorders, mainstream medical opinion considers them more common (though they are also known to occur in those with no pre-existing conditions) $(35,36,42,43)$, in those who have been admitted to hospital $(36,37,42)$.

This study found that $87.4 \%$ reported persistence with at least 1 symptom, particularly fatigue and dyspnea, in patients who had recovered from COVID-19 (36).

They subsequently complained of a relapse of chronic symptoms, in particular myalgia, extreme weakness, fever, dyspnea, tightness of the chest, tachycardia, headaches and anxiety (44).

Interestingly few of them show biological anomalies (no lymphocytopenia or elevated C-reactive protein in particular) and in rare cases, chest computed tomographic scan traces of infection (44). COVID-19 laboratory markers are not specific and are of minimal clinical benefit (12).

Lymphocytopenia and an increase in CRP values are the most commonly reported laboratory anomalies in the literature $(45,46)$.

In our study, when the laboratory values of individuals whose symptoms continued after 1 month were examined both the initial and 1 month later D-dimer and CRP values were found to be higher for those with symptoms.

D-dimer levels are commonly increased in patients infected with COVID-19. Significantly higher levels are found in those with critical illness and can be used as a prognostic marker for in hospital mortality (47).

\section{CONCLUSION}

Symptoms may persist for a long time in hospitalized patients, in patients with COVID-19-related pneumonia and concomitant chronic diseases and in patients with high d-dimer and high CRP at the time of admission. Patients are informed that their symptoms may last for a long time, unnecessary hospital admissons can be avoided.

Funding sources : All support for this study came from institutional and departmental resources. 
Conflict of interest : We declare that there is no conflict of interest, in particular no financial funding potentially relevant to the contents of manuscript.

\section{REFERENCES}

1. Ministry of Health Directorate-General for Public Health Guide to COVID-19. Scientific Advisory Board Study 2 August 2020

2. Del Rio C, Malani P.N. COVID-19-New insights on a rapidly changing epidemic. J Am Med Assoc. 2020 Feb 28

3. Zhou P, Yang XL, Wang XG, et al. A pneumonia outbreak associated with a new coronavirus of probable bat origin. Nature. 2020;579 (7798): 270-273.

4. YR Cao QD, Hong ZS, et al. The origin transmission and clinical therapies on coronavirus disease 2019 (COVID-19) outbreak an update on the status. Mil Med Res. 2020; 7 (1): 11

5. Huang C. Wang Y, Li X, et al. Clinical features of patients infected with 2019 novel coronavirus in Wuhan. China. Lancet. 2020; 395 (10223): 497-506.

6. Zhu W, Xie K, Lu H, Xu L, Zhou S, Fang S. Initial clinical features of suspected coronavirus disease 2019 in two emergency departments outside of Hubei, China. J Med Virol. 2020. 10.1002 / jmv.25763

7. Liu Y, Mao B, Liang S, et al. Association between age and clinical characteristics and outcomes of COVID-19. Eur Respir J 2020; 55: 2001112

8. Guneyli S, Atceken Z, Doğan H, Altınmakas E, Atasoy KÇ. Radiological approach to COVID-19 pneumonia with an emphasis on chest CT. Diagn Interv Radiol 2020; 26:323-332.

9. Wang $\mathrm{D}, \mathrm{Hu} \mathrm{B}, \mathrm{Hu} \mathrm{C}$, et al. Clinical characteristics of 138 hospitalized patients with 2019, novel coronavirus-infected pneumonia in Wuhan. China. JAMA. 2020, 323:1061-1069.

10. Baloch S, Baloch MA, Zheng T, Pei X. The Coronavirus Disease 2019 (COVID-19) Pandemic. Tohoku J Exp Med. 2020 Apr;250(4):271-278.

11. Aggarwal S, Garcia-Telles N, Aggarwal G, Lavie C, Lippi G, Henry BM. Clinical features, laboratory characteristics, and outcomes of patients hospitalized with coronavirus disease 2019 (COVID-19): early report from the United States. Diagnosis (Berl). 2020;7(2):91-6.

12. Guneysu F, Yurumez Y, Guclu E, et al. The diagnostic process of COVID-19 in the emergency department: laboratory and imaging methods. Revista da Associação Médica Brasileira , 2020,66: 2, $58-64$

13. Li R, Liu G, Huang X, et al. Dynamic changes in clinical and CT characteristics of COVID-19 cases with different exposure histories: a retrospective study. BMC Infect Dis. 2020 Aug 3;20(1):567.

14. Akcay S, Ozlu T, Yilmaz A. Radiological approaches to COVID-19 pneumonia. Turk J Med Sci (2020) 50: $604-610$

15. Zhao W, Zhong Z, Xie X, Yu Q, Liu J. Relation between chest CT findings and clinical conditions of coronavirus disease (COVID-19) pneumonia: a multicenter study. AJR Am J Roentgenol 2020; 1-6

16. Shi H, Han X, Jiang N, et al. Radiological findings from 81 patients with COVID-19 pneumonia in Wuhan, China: a descriptive study. Lancet Infect Dis 2020; 20:425-434

17. Ai T, Yang Z, Hou H, et al. Correlation of chest CT and RT-PCR testing in coronavirus disease 2019 (COVID-19) in China: A report of 1014 cases. Radiology 2020 Feb 26

18. Li X, Zeng X, Liu B, Yu Y. COVID-19 infection presenting with CT halo sign. Radiology 2020 Feb 12.

19. Franquet T. Imaging of pulmonary viral pneumonia. Radiology 2011; 260:18-39

20. Huang C, Wang Y, Li X. et al. Clinical features of patients infected with 2019 novel coronavirus in Wuhan. China. Lancet. 2020,395:497-506.

21. Guan WJ, Ni ZY, Hu Y, et al. Clinical characteristics of coronavirus disease 2019 in China. N Engl J Med. 2020 382:1708-1720.

22. Recalcati S. Cutaneous manifestations in COVID-19: a first perspective. J Eur Acad Dermatol Venereol. 2020 34:212-213.

23. Zhonghua LX, Bing X, Za Z Epidemiology Working Group for Ncip Epidemic Response CCfDC. Prevention. [The epidemiological characteristics of an outbreak of 2019 novel coronavirus diseases (COVID19) in China. 2020. 41:145-151. 
24. Nishiura H, Kobayashi T, Miyama T. et al. Estimation of the asymptomatic ratio of novel coronavirus infections (COVID-19). Int J Infect Dis. 2020, 94:154-155.

25. Mizumoto K, Kagaya K, Zarebski A, Chowell G. Estimating the asymptomatic proportion of coronavirus disease 2019. (COVID-19) cases on board the Diamond Princess cruise ship. Yokohama. Japan. 2020. Euro Surveill. 2020. 25:2000180.

26. Ki M. Task Force for -nCo V. Epidemiologic characteristics of early cases with 2019 novel coronavirus (2019-nCoV) disease in Korea. Epidemiol Health. 2020 42:e2020007.

27. Lu X, Zhang L, Du H. et al. SARS-CoV-2 Infection in Children. N Engl J Med. 2020 382:1663-1665.

28. Kimball A, Hatfield KM, Arons M, et al. Asymptomatic and presymptomatic SARS-CoV-2 infections in residents of a long-term care skilled nursing facility- king county. Washington. March 2020. MMWR Morb Mortal Wkly Rep. 2020, 69:377-81.

29. Sonmez O. Taşdemir ZA. Kara H V. Akçay S. Tobacco and COVID-19. Eurasian J Pulmonol 2020;22. Suppl S1:12-5.

30. Morse JS, Lalonde T, Xu S, Liu W. Learning from the past: possible urgent prevention and treatment options for severe acute respiratory infections Li et al. BMC Infectious Diseases (2020) 20:567 Page 13 of 14 caused by 2019-nCoV. Chembiochem. 2020;21(5):730-738.

31. Lu H. Drug treatment options for the 2019-new coronavirus (2019-nCoV). Biosci TrendsPublished online 28 January. 2020.

32. Perego E, Callard F, Stras L, Melville-JÛhannesson B, Pope R, Alwan N. Why the Patient-Made Term 'Long Covid' is needed [version 1; peer review: awaiting peer review]. Wellcome Open Res. 2020;5,224.

33. Greenhalgh T, Knight M, Buxton M, Husain L. Management of post-acute covid-19 in primary care. Bmj. 2020;370:m3026. 3.

34. COVID Symptom Study. How long does COVID-19 last? (blog). London: Kings College London. https://covid.joinzoe.com/post/covid-long-term 2020. Accessed 1 Oct 2020

35. Assaf G, Davis H, McCorkell L, (on behalf of the COVID-19 Body Politic Slack Group). An Analysis of the Prolonged COVID-19 Symptoms Survey by Patient-Led Research Team. Patient Led Res. 2020.https://patientresearchcovid19.com/

36. Carfì A, Bernabei R, Landi F. Persistent symptoms in patients after acute COVID-19. JAMA. 2020;324:603-5

37. Arnold DT, Hamilton FW, Milne A, et al, Gunning S, Hatrick J, Hamilton S. Patient outcomes after hospitalisation with COVID-19 and implications for follow-up; results from a prospective UK cohort. medRxiv. 2020.

38. Goërtz YM, Van Herck M, Delbressine JM, et al. Persistent symptoms 3 months after a SARS-CoV-2 infection: the post-COVID-19 syndrome? ERJ Open Res. 2020;6:00542-2020.

39. Vaes AW, Machado FV, Meys R, et al.. Care dependency in nonhospitalized patients with COVID-19. J Clin Med. 2020;9(9):2946

40. Dhont S, Derom E, Van Braeckel E, Depuydt P, Lambrecht BN. The pathophysiology of 'happy' hypoxemia in COVID-19. Respir Res. 2020;21(1):198

41. Ladds, E, Rushforth, A, Wieringa, S. et al. Persistent symptoms after Covid-19: qualitative study of 114 "long Covid" patients and draft quality principles for services. BMC Health Serv Res 2020, 20, 1144 .

42. Tenforde M, Kim S, Lindsell C, et al. Symptom Duration and Risk Factors for Delayed Return to Usual Health Among Outpatients with COVID-19 in a Multistate Health Care Systems Network - United States, March-June 2020. MMWR Morb Mortal Wkly Rep. 2020, ePub: 24 July 2020.

43. Halpin SJ, McIvor C, Whyatt G, et al. Postdischarge symptoms and rehabilitation needs in survivors of COVID-19 infection: a cross-sectional evaluation. J Med Virol. 2020;30

44. Davido, B., Seang, S., Tubiana, R., \& de Truchis, P. Post-COVID-19 chronic symptoms: a postinfectious entity? Clinical microbiology and infection: the official publication of the European Society of Clinical Microbiology and Infectious Diseases , 2020, 26 (11), 1448-1449.

45. Nikpouraghdam M, Jalali Farahani A, Alishiri G, et al. Epidemiological characteristics of coronavirus disease 2019 (COVID-19) patients in Iran: a single center study. J Clin Virol. 2020;127:104378 
46. Jaillon S, Berthenet K, Garlanda C. Sexual dimorphism in innate immunity. Clin Rev Allergy Immunol. 2019;56(3):308-21.

47. Yao. Y, Cao. J, Wang Q. et al. D-dimer as a biomarker for disease severity and mortality in COVID-19 patients: a case control study. $j$ intensive care 2020, 8. 49

Table 1. General characteristics of the study group

\begin{tabular}{llll}
\hline \multirow{3}{*}{ Gender } & & $\mathrm{N}$ & $\%$ \\
Age & Female & 158 & 50.2 \\
\multirow{2}{*}{ Thorax CT } & $<65$ & 157 & 49.8 \\
& {$[?] 65$} & 270 & 85.7 \\
& No & 45 & 14.3 \\
& Ground glass opacities & 108 & 34.3 \\
& Ground glass opacities & 4 & 50.8 \\
& and thrombus & & 1.3 \\
& Consolidation & 30 & \\
Chest X- rays & Consolidation + & 12 & 9.5 \\
Treatment & ground glass opacities & & 3.8 \\
& Nodular Infiltration & 1 & \\
Normal & 108 & 0.3 \\
Smoking Behavior & Infiltration & 207 & 34.3 \\
& Favipiravir & 185 & 65.7 \\
Treatment place & Favipravir and & 52 & 58.7 \\
Comorbidities & Hidroksiklorokin & & 16.5 \\
& Hidroksiklorokin & 78 & \\
& Non smoker & 197 & 24.8 \\
& Ex smoker & 53 & 62.5 \\
& Current Smoker & 65 & 16.8 \\
& Hospital & 94 & 20.6 \\
& Home & 221 & 29.8 \\
& No & 182 & 70.2 \\
& Yes & 133 & 57.7 \\
\hline
\end{tabular}

CT: Computed Tomography

Table 2. Distribution of symptoms of the study group by periods

\begin{tabular}{lllllll}
\hline \multirow{5}{*}{ Fever } & & First & First & After 1 month & After 1 month & Test Value \\
& & $\mathrm{N}$ & $\%$ & $\mathrm{~N}$ & $\%$ & $\mathrm{p}$ \\
Weakness & No & 216 & 68.6 & 310 & 98.4 & $<0.001$ \\
& Yes & 99 & 31.4 & 5 & 1.6 & \\
Myalgia & No & 248 & 78.7 & 246 & 78.1 & 0.913 \\
& Yes & 67 & 21.3 & 69 & 21.9 & \\
Diarrhea & No & 223 & 70.8 & 273 & 86.7 & $<0.001$ \\
& Yes & 92 & 29.2 & 42 & 13.3 & \\
Dyspnea & No & 305 & 96.8 & 314 & 99.7 & 0.004 \\
& Yes & 10 & 3.2 & 1 & 0.3 & \\
Cough & No & 223 & 70.8 & 242 & 76.8 & 0.023 \\
& Yes & 92 & 29.2 & 73 & 23.2 & \\
& No & 195 & 61.9 & 265 & 84.1 & $<0.001$ \\
& Yes & 120 & 38.1 & 50 & 15.9 &
\end{tabular}




\begin{tabular}{lllllll} 
Loss of taste and smell & No & 291 & 92.4 & 313 & 99.4 & $<0.001$ \\
& Yes & 24 & 7.6 & 2 & 0.6 & \\
Sore throat & No & 287 & 91.1 & 314 & 99.7 & $<0.001$ \\
\multirow{3}{*}{ Sputum } & Yes & 28 & 8.9 & 1 & 0.3 & \\
\multirow{3}{*}{ Other } & No & 304 & 96.5 & 312 & 99.0 & 0.057 \\
\multirow{2}{*}{ At least one symptom } & Yes & 11 & 3.5 & 3 & 1.0 & \\
& No & 275 & 87.3 & 288 & 91.4 & 0.106 \\
& Yes & 40 & 12.7 & 27 & 8.6 & \\
& No & 22 & 7.0 & 86 & 27.3 & $<0.001$ \\
\hline
\end{tabular}

McNemar Test was used

Table 3. Distribution of some laboratory values of the study group according to the periods

\begin{tabular}{|c|c|c|c|c|c|c|c|}
\hline & First & First & First & $\begin{array}{l}\text { After } 1 \\
\text { month }\end{array}$ & $\begin{array}{l}\text { After } 1 \\
\text { month }\end{array}$ & $\begin{array}{l}\text { After } 1 \\
\text { month }\end{array}$ & Test Value \\
\hline & Median & IQR 25 & IQR 75 & Median & IQR 25 & IQR 75 & $\mathrm{p}$ \\
\hline $\begin{array}{l}\text { Neutrophil } \\
\%\end{array}$ & 62.15 & 52.95 & 69.10 & 59.00 & 51.70 & 65.00 & $<0.001$ \\
\hline $\begin{array}{l}\text { Lymphocyte } \\
\%\end{array}$ & 26.00 & 17.75 & 33.50 & 27.00 & 21.20 & 34.20 & 0.091 \\
\hline NLR & 2.43 & 1.67 & 3.70 & 2.20 & 1.57 & 2.99 & 0.001 \\
\hline Platelet & 234.00 & 190.00 & 276.50 & 272.00 & 227.00 & 335.00 & $<0.001$ \\
\hline D-Dimer & .40 & .24 & .78 & .41 & .25 & .68 & 0.001 \\
\hline Ferritin & 82.00 & 24.60 & 198.20 & 62.50 & 22.00 & 223.00 & 0.060 \\
\hline CRP & 8.10 & 3.00 & 26.33 & .87 & .00 & 4.90 & $<0.001$ \\
\hline
\end{tabular}

Wilcoxon Test was used

NLR: Neutrophil/ Lymphocyte Ratio, CRP: C-reaktive protein

Table 4. Distribution of general characteristics of the study group according to the presence of

symptoms 1 month later

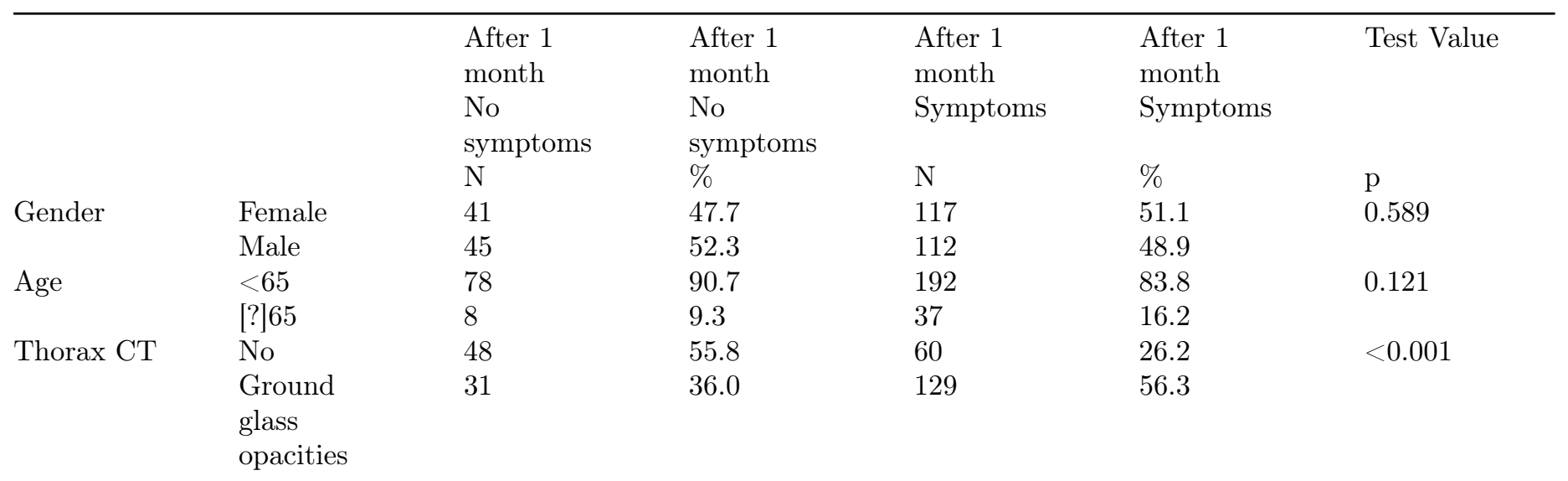




\begin{tabular}{|c|c|c|c|c|c|c|}
\hline & $\begin{array}{l}\text { Ground } \\
\text { glass } \\
\text { opacities } \\
\text { and } \\
\text { thrombus }\end{array}$ & 0 & 0.0 & 4 & 1.7 & \\
\hline & Consolidation & 5 & 5.8 & 25 & 10.9 & \\
\hline & $\begin{array}{l}\text { Consolidation } \\
+ \text { ground } \\
\text { glass } \\
\text { opacities }\end{array}$ & 2 & 2.3 & 10 & 4.4 & \\
\hline & $\begin{array}{l}\text { Nodular } \\
\text { Infiltration }\end{array}$ & 0 & 0.0 & 1 & 0.4 & \\
\hline \multirow[t]{2}{*}{$\begin{array}{l}\text { Chest X } \\
\text {-rays }\end{array}$} & Normal & 48 & 55.8 & 60 & 26.2 & $<0.001$ \\
\hline & Infiltration & 38 & 44.2 & 169 & 73.8 & \\
\hline \multirow[t]{4}{*}{ Treatment } & Favipiravir & 45 & 52.3 & 140 & 61.1 & 0.004 \\
\hline & $\begin{array}{l}\text { Favipravir } \\
\text { and }\end{array}$ & 9 & 10.5 & 43 & 18.8 & \\
\hline & Hidroksiklorokin & & & & & \\
\hline & Hidroksiklorokin & 32 & 37.2 & 46 & 20.1 & \\
\hline \multirow{3}{*}{$\begin{array}{l}\text { Smoking } \\
\text { Behavior }\end{array}$} & Non smoker & 46 & 53.5 & 151 & 65.9 & 0.117 \\
\hline & Ex smoker & 17 & 19.8 & 36 & 15.7 & \\
\hline & $\begin{array}{l}\text { Current } \\
\text { Smoker }\end{array}$ & 23 & 26.7 & 42 & 18.3 & \\
\hline \multirow{2}{*}{$\begin{array}{l}\text { Treatment } \\
\text { place }\end{array}$} & Hospital & 8 & 9.3 & 86 & 37.6 & 0.001 \\
\hline & Home & 78 & 90.7 & 143 & 62.4 & \\
\hline \multirow{2}{*}{ Comorbidities } & No & 68 & 79 & 114 & 49 & $<0.001$ \\
\hline & Yes & 18 & 21 & 115 & 51 & \\
\hline
\end{tabular}

$\mathrm{X}^{2}$ test was used

CT: Computed Tomography

Table 5. Distribution of laboratory values of the study group according to the presence of symptoms after 1 month

\begin{tabular}{lllllll}
\hline & After 1 month & After 1 month & After 1 month & After 1 month & After 1 month & After \\
& No symptoms & No symptoms & No symptoms & Symptoms & Symptoms & Symp \\
& Median & IQR 25 & IQR 75 & Median & IQR 25 & IQR \\
First Neutrophil \% & 58.80 & 50.40 & 67.55 & 62.55 & 55.75 & 70.25 \\
First Lymphocyte $\%$ & 26.70 & 21.00 & 35.65 & 24.90 & 17.40 & 32.15 \\
First NLR & 2.25 & 1.47 & 3.24 & 2.48 & 1.76 & 3.78 \\
First Platelet & 228.00 & 188.50 & 270.50 & 237.50 & 191.50 & 279.00 \\
First D-dimer & .32 & .21 & .53 & .46 & .26 & .90 \\
First Ferritin & 73.00 & 18.40 & 188.00 & 86.00 & 25.00 & 211.00 \\
First CRP & 4.44 & 1.42 & 14.36 & 12.00 & 3.90 & 41.00 \\
After 1 month Neutrophil \% & 58.10 & 49.20 & 63.40 & 59.10 & 52.00 & 66.00 \\
After 1 month Lymphocyte $\%$ & 28.70 & 22.00 & 36.00 & 26.70 & 19.80 & 33.70 \\
After 1 month NLR & 2.10 & 1.56 & 2.67 & 2.21 & 1.57 & 3.09 \\
After 1 month Platelet & 247.50 & 215.00 & 282.00 & 280.00 & 233.00 & 343.00 \\
& & & & & &
\end{tabular}


After 1 month D-dimer

After 1 month Ferritin

After 1 month CRP
.37

47.00

.00
.20

13.00

.00
.53

138.00

2.00
.44

65.30

62.55
.27

23.00

55.75
.74 235.00 70.25

Mann Whitney U test was used

NLR: Neutrophil/ Lymphocyte Ratio, CRP: C-reaktive protein

Table 6. Distribution of laboratory values according to the treatment received by the study group

\begin{tabular}{|c|c|c|c|c|c|}
\hline & Treatment & Treatment & Treatment & Treatment & Treatm \\
\hline & Favipiravir ${ }^{1}$ & Favipiravir ${ }^{1}$ & Favipiravir ${ }^{1}$ & Favipravir and Hydroxychloroquine ${ }^{2}$ & Favipra \\
\hline & Median & IQR 25 & IQR 75 & Median & IQR 25 \\
\hline First Neutrophil \% & 62.15 & 54.80 & 70.20 & 63.75 & 57.35 \\
\hline First Lymphocyte \% & 26.55 & 17.50 & 33.30 & 23.25 & 16.75 \\
\hline First NLR & 2.45 & 1.69 & 3.65 & 3.02 & 1.91 \\
\hline First Platelet & 224.00 & 191.00 & 283.00 & 221.50 & 182.00 \\
\hline First D-dimer & .45 & .26 & .83 & .54 & .35 \\
\hline First Ferritin & 62.90 & 19.10 & 211.00 & 120.40 & 41.20 \\
\hline First CRP & 13.00 & 4.00 & 44.33 & 9.20 & 3.19 \\
\hline After 1 month Neutrophil $\%$ & 57.40 & 52.50 & 65.80 & 60.00 & 49.50 \\
\hline After 1 month Lymphocyte \% & 25.85 & 17.95 & 32.70 & 24.55 & 18.75 \\
\hline After 1 month NLR & 2.29 & 1.62 & 3.21 & 2.28 & 1.54 \\
\hline After 1 month Platelet & 282.00 & 232.50 & 343.50 & 267.00 & 229.00 \\
\hline After 1 month D-dimer & .42 & .30 & .80 & .46 & .31 \\
\hline After 1 month Ferritin & 73.00 & 22.00 & 265.00 & 57.00 & 29.10 \\
\hline After 1 month CRP & .40 & .00 & 4.50 & 3.29 & .87 \\
\hline
\end{tabular}

Kruskal-Wallis Test was used. First D-dimer 1-2: 0.357 1-3:<0.001 2-3: $<0.001$, First CRP 1-2:0.422 1-3: $<0.001$ 2-3: 0.058, After 1 month 1-2: 0.087 1-3: 0.004 2-3: 1.000, After 1 month D-dimer 1-2: 1.000 1-3:0.024 2-3:0.033, After 1 month CRP 1-2:<0.001 1-3: 1.000 2-3: <0.001

NLR: Neutrophil/ Lymphocyte Ratio, CRP: C-reaktive protein 